\title{
IDENTIDADE, ACEITAÇÃO E LUTAS EM BLESS ME, ULTIMA DE RUDOLFO ANAYA
}

Gilberto Zolotorevsky Alves Junior ${ }^{1}$

Resumo: O romance Bless me, Ultima de Rudolfo Anaya, um dos precursores da Literatura Chicana, traz os conflitos vividos pelos chicanos na sua luta por inclusão e identidade na sociedade norte-americana. Para entender tais lutas, precisamos primeiramente entender o panorama histórico e sociocultural no qual a obra esta inserida e identificar alguns fenômenos culturais e aspectos ideológicos envolvidos. Este estudo será embasado em pressupostos dos Estudos Culturais, levando em consideração fatores como aceitação social, busca por identidade, barreiras raciais e preconceito social. O trabalho também analisa alguns aspectos referentes à maneira na qual a Literatura Chicana está promovendo modificações e inclusões no cânone, na tradição literária, lançando um novo olhar sobre a tradição literária vigente. Anaya traz em sua obra um dos pontos cruciais para esse movimento de afirmação da literatura produzida por hifenados, identificando e pontuando alguns elementos que possam traçar o surgimento e o desenvolvimento de uma literatura própria aos chicanos e entender como a forma dos conflitos sociais se sedimenta na própria forma do romance. É essencial estudar a produção literária de grupos que ficaram por muito tempo à margem da literatura norte-americana, tratando de temas que envolvem outra perspectiva, confrontando a cultura de hegemonia branca e dominante, com uma estória sendo contada do ponto de vista do colonizador. Problematizar, tentar entender um pouco mais sobre as lutas, vitórias e derrotas traduzidas em literatura que os autores chicanos, em especial Rudolfo Anaya em sua obra Bless me, Ultima, trazem ao leitor.

Palavras-chave: Literatura Chicana. Bless me, Ultima. Rudolfo Anaya. Identidade.

Abstract: The novel Bless Me, Ultima by Rudolfo Anaya, one of the pioneers in Chicano Literature brings conflicts experienced by Chicanos in their fight for inclusion and identity in American society. In order to understand such struggles, we must first understand historical and socio-cultural panorama in which the work is inserted, and identify some cultural phenomena and ideological aspects involved. The following study will be grounded in assumptions of cultural studies, taking into account factors such as social acceptance, search for identity, racial barriers, and social prejudice. It also goes through some aspects of the way in which Chicano Literature is promoting changes and additions to the canon, in literary tradition, giving a new look on the current literary scenario. Anaya brings in his work one of the crucial points for this assertion movement of the literature produced by hyphenated, identifying and scoring some elements that can trace the emergence and

\footnotetext{
${ }^{1}$ Mestrando em Estudos Literários do Programa de Pós-Graduação em Letras da UFSM. Orientadora Prof. ㅁ. Dr. Vera Lúcia Lenz Vianna da Silva. E-mail: gibazjr@gmail.com
} 
development of its own literature to Chicanos and understand how the form of social conflicts settles in the novel itself. It is essential to study the literature of groups that were long on the margins of American literature, dealing with issues involving another perspective, confronting the culture of white and dominant hegemony, with a story being told from the point of view of the colonized. Questioning, trying to understand a little more about the struggles, victories and defeats translated into literature that Chicanos authors, especially Rudolfo Anaya in his work Bless me, Ultima brings to the reader.

Keywords: Chicano Literature. Bless me, Ultima. Rudolfo Anaya. Identity.

\section{INTRODUÇÃO}

Rudolfo Alfonso Anaya nasceu na zona rural da cidade de Pastura, New Mexico, e foi criado nas proximidades em uma pequena cidade chamada Santa Rosa. Seu pai era um fazendeiro de uma família de criadores de gado e de ovelhas. Anaya tem formação em Inglês e literatura norte-americana pela University of New Mexico, na qual se formou em 1963. Concluiu, posteriormente, dois mestrados na área.

Anaya começou a escrever Bless Me, Ultima, em 1963, completando a obra em 1972. O autor teve problemas ao publicá-la na época devido à sua linguagem que trazia uma combinação de inglês e espanhol. O romance de Rudolfo Anaya traz os conflitos vividos pelo povo na sua luta por inclusão e identidade na sociedade norte-americana. Para entender tais lutas, precisamos primeiramente traçar um panorama histórico e sociocultural no qual a obra esta inserida e identificar alguns fenômenos culturais e aspectos ideológicos envolvidos. Este estudo será embasado em pressupostos dos Estudos Culturais, levando em consideração fatores como aceitação social, busca por identidade, barreiras raciais e preconceito social.

Analisarei também alguns aspectos referentes à maneira pela qual a Literatura Chicana está promovendo modificações e inclusões no cânone, na tradição literária, lançando um novo olhar sobre essa tradição literária vigente. A maneira na qual a obra de Anaya se situa em relação à tradição literária anterior é um dos pontos cruciais para o desenvolvimento deste artigo, identificando e pontuando alguns elementos que possam traçar o surgimento e 
o desenvolvimento de uma literatura própria aos chicanos e entender como a forma dos conflitos sociais se sedimenta na própria forma do romance.

É essencial estudar a produção literária de grupos que ficaram por muito tempo à margem da literatura norte-americana, tratando de temas que envolvem outra perspectiva, confrontando a cultura de hegemonia branca e dominante, com uma estória sendo contada do ponto de vista do colonizador. Problematizar, tentar entender um pouco mais sobre as lutas, vitórias e derrotas traduzidas em literatura que os autores chicanos, em especial Rudolfo Anaya, trazem ao leitor.

De acordo com Torres (2001, p. 13), o cânone está sempre se movendo na direção contrária, resistindo aos grupos chicanos e às suas tentativas de "desconstruir a homogeneidade, não aceitando a língua espanhola e suas variantes". Considerando esta afirmação, faz-se necessário estudar a literatura marginal, de modo a investigar outros sentidos e vozes, pensando em uma proposta de colaborar para que tal literatura esteja um pouco mais perto do centro, um pouco mais em direção às experiências estéticas que trazem outro olhar sobre a cultura e identidade de um povo, em termos históricos e sociais.

A análise da obra de Anaya perpassa as diferentes categorias e conceitos de literatura/linguagem. As ponderações acerca do conceito de exotopia, exemplificando o objetivo em relação à análise da obra, partem das reflexões sobre o universo literário, direcionando-se então para uma discussão cultural, envolvendo cultura própria e a outra cultura.

A discussão vai além, passando pelos diálogos entre o universo artístico e o universo extraliterário, utilizando-se das diferenças e interdependências entre tais campos no desenrolar epistemológico da análise da obra:

O texto [...] não se apresenta como um conjunto de enunciados unificados por posições ideológicas não-conflitantes, como algo homogêneo. Ao contrário, 0 texto se constitui de discursos divergentes cujas fronteiras se intersectam [..]: 0 texto é heterogêneo, não é possível definir um dos discursos sem remeter ao outro (Mussalin, 2004, p. 124).

\section{PANORAMA HISTÓRICO}


Há uma longa história de presença mexicana nos Estados Unidos. Antes de 1848, uma grande porção de terra, hoje parte dos Estados Unidos, pertencia ao México. Após o Tratado de Guadalupe Hidalgo, a Guerra MexicanoAmericana teve seu fim.

O México foi obrigado a vender os estados da Califórnia, Nevada, Utah e partes dos estados do Wyoming e Colorado aos Estados Unidos, que pagaram quinze milhões de dólares pela aquisição do território, que equivale a aproximadamente um sexto do tamanho atual do país. Importante citar o fato de que nesse Tratado havia uma garantia de que os mexicanos que moravam nessa área teriam os mesmos direitos e privilégios dos cidadãos americanos. Fato, entretanto, que não ocorreu. Chicanos são pessoas morando nos Estados Unidos com ancestrais mexicanos. Utiliza-se aqui o termo chicano como sinônimo de mexicano-americano.

A Literatura Chicana pode ser definida como a literatura escrita desde 1848 por americanos com descendência mexicana ou mexicanos nos Estados Unidos que escrevem sobre a experiência mexicano-americana. Os temas que perpassam tal literatura são essencialmente de caráter identitário, exploração social e política, experiências de imigração, a vida nos barrios e a união do povo hispânico, a documentação de preconceitos raciais, dificuldades de adaptação a uma nova cultura e barreiras linguísticas.

A problemática da identidade, da aceitação, do fazer parte, está presente a todo o instante. Não são mais mexicanos e, ao mesmo tempo, não são aceitos como americanos de verdade. Passam a habitar (ter sua identidade em) o que Bahbha (2003) chama de um entre-lugar, vivem no hífen, entre as duas culturas, tendo a "necessidade de passar além das narrativas de subjetividades originárias e iniciais e de focalizar aqueles momentos ou processos que são produzidos na articulação de diferenças culturais" (2003, p. 20). Por conta da sua heterogeneidade, mexicano-americanos são incompreendidos pela sociedade, suscetíveis de uma interpretação errônea.

Aguirre define a representação cultural dos chicanos com as seguintes palavras:

We are not Mexicans. We are citizens of the United States with cultural ties to Mexico and in some instances to Spain, but within our ties of language and culture, we have developed a culture that is 
neither Spanish nor Mexican. [...] Entre nosotros habernos quien habla um español puro, pero también entre nosotros habernos los "batos" que no pueden conseguir "jale" por la razón que sea. (1972, p. 1-5)

Desde seu aparecimento nos anos sessenta, a crítica literária acerca da Literatura Chicana tem sofrido transformações massivas, que se tornam evidentes em sua sofisticação e volume substancial.

\section{ESTUDOS CULTURAIS E CRÍTICA LITERÁRIA}

O mundo passa por transformações rápidas e intensas a partir da segunda metade do século XX. A noção e percepção que o sujeito tem de si e do mundo é modificada, juntamente com os grandes movimentos sociais que impulsionam as discussões sobre as dicotomias de dominador/dominado, opressor/oprimido.

Os estudos culturais lidam com problemas ligados a fatores, como raça, classe social, ideologia e gênero, adaptando-se ao momento histórico, tomando novos rumos e abrindo novas possibilidades de ver a sociedade.

A cultura como objeto de estudo é trazida a partir do início da década de oitenta, com reflexões acerca das relações de poder, identidade, sexualidade e etnicidade.

Intelectuais respeitados como Homi Bhabha, Edward Said e Fredric Jameson dedicam-se aos chamados Estudos Pós-Coloniais, abordando assuntos como pós-modernismo, imperialismo e capitalismo tardio, com ligação aos Estudos Culturais, ajudando no conhecimento dos modos de formação de identidades no mundo atual.

$\mathrm{Na}$ literatura ocidental, as literaturas de "etnias" ainda são marginalizadas, não fazendo parte de um cânone literário, desconsiderando-se seu valor histórico, político e social. Faz-se necessário então compreender o papel da cultura dentro da obra literária e as relações entre tais oposições de centro e margem.

O uso da abordagem cultural no estudo da obra literária remete à análise do político, do social e do econômico no mundo ficcional e a sua relação com o 
real. O real é representado, até certo ponto, no ficcional, retratando as relações entre as diferentes culturas e desfazendo ideias pré-concebidas de uma determinada cultura dominante.

Said (1999, p. 12) afirma que "cultura" designa todas as práticas, como as artes de descrição, comunicação e representação, com certa autonomia nos campos econômico, social e político, e que existem sob formas estéticas, sendo o prazer um de seus principais objetivos.

Formas culturais como o romance são fundamentais na formação de referências e experiências. Pode-se dizer então que as vozes presentes em uma trama romanesca podem moldar a ideia que um povo, uma nação faz de si mesma e de outras.

Um exemplo prático de tal situação é visível em narrativas ocidentais que trazem as personagens de heróis e heroínas com aspectos físicos caucasianos, ao tempo que personagens menos distintos possuem características físicas africanas, indígenas, latinas, afetando a formação identitária dos "Outros" em uma sociedade dominada por brancos.

Saldívar (1981, p. 35) discutiu as vantagens e limitações dos Estudos Culturais quando aplicados à Literatura Chicana e seu discurso literário. $O$ autor traçou a evolução dos Estudos Culturais desde 1980, quando os intelectuais norte-americanos começaram a importar os conceitos britânicos. 0 autor também cita documentos encontrados na Universidade de Birmingham enfatizando que cultura era definida como esforço e resistência material, intelectual e espiritual ao invés de um fenômeno isolado e estático.

A prática de Estudos Culturais na universidade de Birmingham e em qualquer lugar na Grã-Bretanha não era um exercício isolado, mas sim uma intervenção ativa nas lutas da classe trabalhadora.

Saldívar (1981, p. 57) expressa o receio de que tal natureza dinâmica dos Estudos Culturais fosse perdida, tornando-se institucionalizada nas universidades dos Estados Unidos. O autor propõe então um remapeamento dos Estudos Culturais nos Estados Unidos e faz uma pergunta chave: "Como podemos contar outras histórias que passam em outros lugares da consciência e, por outro lado, situadas globalmente, geopoliticamente, em outro?".

Quais seriam as fronteiras/barreiras para considerarmos a Literatura Chicana produzida nos Estados Unidos, por cidadãos norte-americanos, 
nascidos ou não em território americano, como parte do cânone deste país? O que tornava essa literatura, esses escritores, essas vozes como marginais?

Há uma necessidade inerente de, ao trabalhar com literatura de grupos étnicos, buscar analisar elementos que estão expostos na produção da obra, colocando em evidência não apenas os contextos sociais, históricos, políticos e econômicos, mas também a cultura e ideologia presentes em tal produção.

Segundo Carvalhal (2003, p. 63) a heterogeneidade, os processos dinâmicos de transformação cultural e os entrecruzamentos de discursos são elementos constitutivos dos pontos centrais da atenção comparatista.

Pode-se entender, então, que algumas das preocupações dos Estudos Culturais vão ao encontro da preocupação da prática comparatista, promovendo, de certa forma, os deslocamentos da margem para o centro, dando voz às minorias e enriquecendo o cânone literário.

A obra incorpora elementos desse choque cultural, denunciando os conflitos sociais e angústias individuais decorrentes dessas travessias sociais, na luta diária por reconhecimento, aceitação, inclusão, sobrevivência e identidade.

As razões do estudo desta obra passam pelo fato de ela celebrar a etnicidade, em uma tentativa de demonstrar que as culturas hifenadas têm valor e voz dentro da sociedade norte-americana, com os conflitos de personagens em busca da aceitação.

Existe, em Bless me, Ultima, a necessidade de mostrar uma tentativa de reconciliação de tradições culturais conflituosas. Anaya sugere na obra que 0 indivíduo pode perceber diferentes tradições e montar então sua identidade a partir disso. Existem três conflitos básicos na formação identitária de Antônio. O primeiro conflito envolve seus pais. Sua mãe quer que ele seja padre, enquanto seu pai quer que ele seja vaqueiro, para poder assumir o serviço da família no campo. Logo no nascimento do menino, os amigos de Gabriel, pai de Antônio anunciam que "Gabriel, eles gritaram, você tem um filho lindo! Ele vai ser um ótimo Vaquero!" (ANAYA, 1972, p. 12, tradução nossa). O pai tenta de todas as formas mostrar as lidas para o menino, que parece não ter muita vocação para tais. Quando seus tios passam a notar esse fato, criticam o menino de forma velada, porém, ele ouve e reclama para La Grande: "Naquele, não há 
esperança (de se tornar Vaquero). Eu ouvi meu tio Juan falar sobre mim." (ANAYA, 1972, p. 124-125, tradução nossa).

A mãe, no entanto, faz preces para que seu filho se torne um padre e siga a vida sacerdotal. Ela rezava "Mãe de Deus, faça do meu quarto filho um padre" (ANAYA, 1972, p. 157, tradução nossa). Quando a Curandera chegou às terras para morar com a família, a mãe de Antônio pede a ela para dizer, adivinhar o que o menino seria quando crescesse:

\footnotetext{
"Me diga, Grande, por favor, "minha mãe implorou.

"Maria!" Meu pai falou incisivamente.

"Oh, por favor, me diga o que meu filho será", minha mãe olhou ansiosamente para mim e para Ultima.

"Ele será um homem de aprendizados," disse Ultima de forma triste.

"!Madre de Dios! Minha mãe gritou e fez o sinal da cruz. (ANAYA, 1972, p. 52, tradução nossa)
}

A outra relação de conflito de identidade e aceitação diz respeito à sua cidade, que está em um entre-lugar das culturas hispânicas, indígenas e norteamericanas. Há evidência desse conflito no tema central que está relacionado ao folclore místico de Ultima e a Igreja Católica.

Também há o conflito que acontece na escola de Antônio entre falantes de espanhol e inglês, que pelo fato de o menino ter sotaque hispânico, passa a ser ridicularizado pelos colegas, fazendo o menino se questionar sobre sua identidade e qual seria seu lugar naquela comunidade em que as outras crianças falavam "diferente" dele.

\section{Considerações Finais}

Todos os debates que norteiam o assunto de identidade, alteridade, aceitação são de extrema importância no mundo acadêmico e fora dele. Dessa parte dos estudos culturais dependem muitos dos nossos problemas reais e palpáveis relacionados a preconceitos, lutas e discriminações. Faz-se então imperativo tal debate para que não tenhamos mais povos, raças, credos, línguas que sejam deixados à margem da sociedade pelo simples fato de serem "diferentes" do que está no eixo central de uma ou de outra sociedade. É importante também colocar junto ao estudo cultural, a história, para que possamos ser mais críticos em relação ao que está nos livros e não 
simplesmente aceitarmos o que nos é dito de forma passiva, tornando-nos assim sujeitos ativos da história e da cultura, dando a oportunidade de que, por exemplo, ao estudar a Literatura Chicana, ela passe a ser um pouco mais parte do cânone, do centro, processo que vem acontecendo há muito tempo com excelentes conquistas, passando a ocupar um lugar na história e no mundo, confirmando sua identidade e tendo um caminho próprio.

Quando existe a formação identitária dentro do difícil caminho entre uma cultura e outra, entre uma língua e outra, é necessário refletir acerca do fato de que nenhuma cultura é feita por homogêneos, e sim por opostos. Esse trabalho procurou mostrar um pouco desse movimento de resistência que existe em busca da afirmação da identidade Chicana dentro dos Estados Unidos retratado na literatura.

\section{REFERÊNCIAS}

AGUIRRE, Lydia R. La causa chicana: The Movement for Justice. New York, Family Service Association of America, 1972.

ANAYA, Rudolfo A., Bless me, Ultima. Berkeley: Tonatiuh-Quinto Sol International, 1972.

BAKHTIN, Mikhail Mikhailovich. O autor e o herói. In: Estética da criação verbal. Tradução Maria Ermantina Galvão G. Pereira. São Paulo: Martins Fontes, 1997.

BHABHA, Hommi. O local da cultura. Tradução Myriam Ávila, Eliana Lourenço de Lima Reis e Gláucia Renate Gonçalves. Belo Horizonte: UFMG, 2003.

DWYER, Carlota Cardenas. Chicano voices. Boston: The new American Mifflin, 1975.

SAID, Edward. Cultura e imperialismo. Tradução Denise Bottman. São Paulo: Companhia das Letras, 1999.

SALDIVAR, Jose David. The limits of Cultural Studies. Michigan: University of Michigan, 1989.

TATUM, Charles William. Otra voz del pueblo. Agua Negra Boise: Ahsahra Press. 1981.

TORRES, Sonia. Nosotros in USA. Rio de Janeiro: Jorge Zahar, 2001. 